Área Abierta. Revista de comunicación

audiovisual y publicitaria

ISSN: 2530-7592

http://dx.doi.org/10.5209/ARAB.53496

\title{
Realización, lenguaje y elecciones narrativas de radioteatro: tres aproximaciones a la creación de espacios sonoros en el tiempo
}

\author{
Miguel Ángel Ortiz Sobrino ${ }^{1}$; Federico Volpini Sisó ${ }^{2}$
}

Recibido: 19 de septiembre de 2016 / Aceptado: 1 de diciembre de 2016

Resumen. Crear en el ámbito del tiempo un espacio que no existe en ningún otro lugar y hacer que en ese espacio actúen los personajes es lo que denominamos radioteatro. El radioteatro es un género de ficción que tuvo destacada presencia en las principales cadenas de radio españolas hasta finales de la década de los ochenta. Desde entonces, salvo excepciones como, entre 1994 y 2003, las celebradas Sobrenatural e Historias de Juan José Plans en Radio 1 y la apuesta de Radio 3 entre los años 1999 y 2003, con la emisión del serial de Carlos Faraco Cuando Juan y Tula fueron a Siritinga y otras muchas ficciones dramatizadas para radio, el formato ha tenido escaso protagonismo en la radio española. Sin embargo, a partir de la segunda década de este siglo, que ha asistido incluso a la convocatoria del Congreso Internacional de Radioteatro impulsado por la Escuela TEA FM de Zaragoza, ya por su IV edición, crece el interés entre profesionales y estudiantes por el radioteatro. Igualmente, las grandes cadenas empiezan a recuperar, aun tímidamente, este tipo de programas. Dos ejemplos: en la radio pública estatal espacios como su producción estelar serializada El Quijote del siglo XXI, además de otros contenidos de ficción con periodicidad semestral; y, desde la radio privada, en la Cadena SER, la serie de Mónica León Negra y Criminal o el Cuento de Navidad, con el que ha venido felicitando a los oyentes las tres últimas temporadas. En este artículo se aborda el concepto de radioteatro, otras expresiones de ficción radiofónica y el devenir de este género de programación por las parrillas de las principales cadenas de radio a lo largo de su historia. Finalmente, se ofrecen los resultados de tres aproximaciones a la ficción dramatizada para la radio, a través de diferentes maneras de abordar la narración, la acción y el lenguaje radiofónico en tres obras producidas por Radio Nacional de España: Cabeza de Vaca: Las vidas de Alvar Núñez, Herederos del tiempo y El corazón de las tinieblas.

Palabras clave: Radioteatro, audiodrama, lenguaje radiofónico, realización, interpretación

\section{[en] Radio Drama. Production, Language and Narrative Choices: Three Approaches to the Creation of Space in Time}

Abstract. To create on the sole ground of time a space that would not exist elsewhere, and make
characters act in this space: that is what radiodrama is about. The radio drama format had great
presence in Spanish Radio main chains and stations until the late eighties. With some exceptions, such
as, between 1993 and 2003 , the very popular Supernatural and Tales, by Juan José Plans in Radio
1, and the commitment of Radio 3 between 1999 and 2003 , with the serial by Carlos Faraco When
Juan and Tula went to Siritinga and many other fiction features, fiction had since little prominence in
the Spanish radio. However, in the second decade of this century, that has even seen the summoning
of an International Radio Drama Congress, patronized by the TEA FM School of Saragosse, now in

1 Universidad Complutense de Madrid (España)

E-mail: maortiz@ucm.es

2 Programador y guionista de radio

E-mail: cinesporas@gmail.com 
its fourth Edition, the interest grows among professionals and students, and the "majors" in Radio Broadcasting, though timidly, seem to be recovering fiction and bringing it back to their programming schedules. Just two examples: in the public radio the serial Don Quixote of the 21st Century, in addition to other fictional features, programmed every six months; and, in commercial radio, the Cadena SER, the serial by Mónica León Criminal and Black or The Christmas Carol, wich has been it's greeting to the audience the last three seasons. This article deals with the concept of radio theatre and other forms of fictional radio and with the evolution of the format in the radio broadcasting history. It finnaly offers three approaches to fictional drama for radio, and it's results, through three different ways to face narration, action and radio language, in three plays produced by the National Radio of Spain: Cabeza de Vaca: the Many Lifes of Alvar Núñez, Heirs of Time and Heart of Darkness.

Keywords: Radio theater, audio drama, radio language, producing, acting

Sumario. 1. Introducción. 2. La ficción radiofónica como objeto de la literatura científica. 3. Radioteatro, ficción sonora o audioteatro. Aproximación al concepto. 4. Objeto de estudio: Cabeza de Vaca: Las vidas de Alvar Núñez, Herederos del Tiempo y El corazón de las tinieblas. 5. El trabajo en los tres audioteatros. 6. Conclusiones. 7. Bibliografía. 8.Archivos sonoros

Cómo citar: Ortiz Sobrino, M. A y Volpini Sisó, F. (2017) Realización, lenguaje y elecciones narrativas de radioteatro: tres aproximaciones a la creación de espacios sonoros en el tiempo, en Área Abierta. Revista de comunicación audiovisual y publicitaria 17 (1), 13-36. http://dx.doi.org/10.5209/ ARAB.53496

\section{Introducción}

En la primavera de 2005, el entonces director de Radio 3, José Antonio Martín Morán, convocó una encuesta entre los oyentes de la que se define como emisora joven de Radio Nacional. La respuesta no dejó de sorprenderle: «me piden ficción», nos relataba en el Festival de Benicassim de ese año. Ni más música, ni más actualidad: espacios dramáticos. Aquel mismo año, el director de Radio Nacional de España (RNE), Pedro Piqueras, con ocasión del premio que habían obtenido dos de los alumnos del Master de la radio pública, Lourdes Castro y Álvaro Soto, por su ficción dramatizada Sentidos oídos en el Open Radio del CCB de Barcelona, preguntó a qué quería esa promoción dedicarse profesionalmente. La práctica totalidad de los treinta y tantos jóvenes alumnos del Master quería hacer dramáticos. Una promoción especial, pero no rara.

Durante los veinte años, entre 1989 y 2009, que ejercimos, en el Master de RNE Miguel Ángel Ortiz Sobrino como director y Federico Volpini Sisó como profesor de guión y realización, invariablemente una parte considerable de los alumnos, siempre por encima del cincuenta por ciento, se decidía por el radioteatro. No información, no opinión, no tertulias: ficción. Cierto que ese interés no derivó en un cambio, por lo que a la presencia del género en la emisora se refiere. Nada cambia.

Antes, en los años noventa, tras la desaparición de los espacios dramáticos, Ignacio María Sanuy, director del programa El defensor del oyente de RNE comentaba en antena que gran parte de sus comunicantes solicitaba la vuelta de los radioteatros. Algo parecido ocurría, también, en la radio privada donde, en 1988, había dejado de emitirse en la Cadena SER el serial radiofónico La saga de los Porretas, probablemente el último exponente de los seriales clásicos de la radio privada. Apenas tres ejemplos, pero reveladores. 
Podría deducirse que el radioteatro, un género de siempre, es asimismo un género de hoy, como se manifiesta en las representaciones de la Sala Triángulo (2010), o en el II y III Congresos de radioteatro (2013 y 2015), o en el Festival de Teatro Clásico de Alcalá de Henares y en Ciclo de Teatro Clásico de Toledo (2016). Hasta aquellos que no han tenido, o han tenido muy someramente,, ocasión de conocerla en las ondas, se sienten seducidos por la ficción radiofónica cuando acceden a ella en sus periodos de formación integral en las radios universitarias (Ortiz Sobrino, Marta Lazo y Martín Pena, 2016: 42). ¿Por qué, pues, se eliminó el radioteatro de la programación en la radio española?

¿No pudo obedecer la desaparición de este tipo de contenidos, oficiada por informadores a los que el mero concepto de ficción estorba, a una decisión política (desmarcarse de cuanto pudiera recordar al régimen franquista); a una discutible idea de modernidad: los radioteatros les sonaban antiguos; y a una gestión particularista, interesada, gremial incluso, de los medios? Se nos antojaría absurdo aducir como causa la oferta televisiva. La televisión no ha desplazado a la radio en ningún otro de sus contenidos y la ficción radiofónica juega cartas que a la imagen le están vedadas: vivir las historias desde dentro, sin que se impongan rostros, caracteres. No parece serio, tampoco, defender que el coste de la producción sea argumento decisivo: hay contenidos radiofónicos más caros como cualquier informativo (redacciones enteras a jornada completa, corresponsales, unidades móviles), los programas de estrellas o determinadas tertulias. Sí tendría más que ver con el conocimiento, la especificidad de su propuesta, la capacitación de sus profesionales. Con el rendimiento que pretende obtenerse de la radio. Con estrategias comerciales y estrategias asimismo políticas.

La radio comercial, generalmente, busca un beneficio que le complique lo menos posible. En las radios públicas españolas las distintas administraciones buscan votos. «El radioteatro, obra de profesionales cualificados que no puede improvisarse, para la radio privada no es rentable. Para la radio pública, el radioteatro no sólo no da votos, sino que no es inocuo: puede ampliar la exigencia en vez de reducirla» (Volpini en González Alfonsea, 2016). El radioteatro requiere profesionales cualificados, interdependientes, así como contenidos discrecionales que exigen criterios precisos.

Aun así, la realidad es tozuda. Uniéndose a sus mayores, buena parte de los jóvenes, cuando conocen la ficción dramatizada, muestran interés tanto en su escucha como en la profesión. Internet, la radio y las nuevas plataformas son canales donde emitir estos contenidos. Falta la oferta y el compromiso decidido de los responsables del sector radiofónico. El radioteatro es hoy, bien género de excepción, bien guerrilla urbana, voluntarismo, lucha contra los elementos.

Pero parece que se evidencia en las grandes cadenas la voluntad de recuperar la ficción radiofónica, aunque sólo sea como género de culto. Así viene ocurriendo con la radio pública estatal. Tras Sobrenatural e Historias (pertenecientes, ambas, al muy eficaz genero de terror) y el paréntesis que abre Radio 3 con la programación habitual de espacios dramatizados entre 1999 y 2003, en 2011 el teatro radiofónico volvió a Radio Nacional de España en una colaboración con la Fundación Autor, con obras cortas de creadores españoles. Igualmente, la colaboración de la radio pública con el festival de teatro de Almagro ha dado paso a series de ficción como las Noches de miedo en Radio Nacional (SGAE, 2011). Hablaremos después del proyecto Ficción Sonora del que han resultado obras dramáticas como la mencionada El Quijote del siglo XXI. 
También desde la radio privada se atiende al radioteatro en los últimos años. Hemos mencionado Negra y criminal y las tres temporadas del Cuento de Navidad en la Cadena SER, que estrenó recientemente la obra ;Qué bello es vivir! (Zumeta, 2015). Hoy las webs de la Cadena Ser (la plataforma Podium Podcast) y de Radio Nacional de España ofrecen los podcast de muchas de estas producciones emblemáticas en una perfecta hibridación de Internet con la digitalización de los archivos de las cadenas radiofónicas (Ortiz Sobrino, 2012; Marta Lazo y Ortiz Sobrino 2013 y Gordillo Álvarez et al, 2011).

\section{La ficción radiofónica como objeto de la literatura científica}

La literatura científica ha puesto de manifiesto la presencia de la ficción radiofónica en la radio española. En ella se encuentran completos estudios sobre el radioteatro y las radionovelas, desde prácticamente sus inicios hasta que fueron perdiendo protagonismo en las programaciones de las principales cadenas de radio (Barea, 1994, 2002, 2003 y 2004). También en ella se recogen contribuciones sobre la ficción radiofónica en el contexto histórico radiofónico (Díaz, 1993; Balsebre, 2001 y 2002; Franquet, 1999). Del impacto social de la radionovela ya se tienen referencia en los primeros años de la década de 1950. Ayuso (2013) narra su influencia en la audiencia femenina de la época. Los principales espacios eran radionovelas, teatro y consultorios femeninos: el más popular, El Consultorio de Elena Francis. De igual forma, en el trabajo de Arias García (2008) sobre Ama Rosa, una referencia ineludible en la radionovela española, se aborda el análisis de la estructura de los seriales radiofónicos. Otros, como López Merayo (2012) han estudiado determinado género literario y su adaptación radiofónica.

Por su parte, Guarinos (1999) y Rodero y Soengas (2010) han abordado los aspectos teóricos y prácticos para elaborar historias de ficción en radio. Sin embargo, como manifiesta Ayuso «avanzada la década de los sesenta, con la llegada de la televisión y el aperturismo en la política informativa de la transición democrática, la radio se adaptará de nuevo y, ya en los inicios de la década de los setenta, daría paso a una programación lanzada a la conquista de la información, dejando de lado las emisiones de programas dramáticos» (2013).

La última emisión en 1988 del serial radiofónico La saga de los Porretas de la Cadena Ser, puede considerarse el último vestigio de la continuidad de los tradicionales radioteatros y seriales radiofónicos de las grandes cadenas españolas (Díaz, 1993). Un punto de inflexión en relación no solo con su presencia en la programación, sino también en los formatos de ficción radiofónica que luego se irán incorporando a la radio, bien como ingredientes de la programación de entretenimiento y la publicidad, o bien como ficciones en las que se simultanea la emisión radiofónica con la representación ante el público: éste es el caso del programa Ficción Sonora (Arquero, 2015), una producción de Radio Nacional de España que ya hemos mencionado y sobre la que volveremos.

\section{Radioteatro, ficción sonora o audioteatro. Aproximación al concepto}

Los profesionales y teóricos del medio no acaban de ponerse de acuerdo en un 
término unívoco para denominar los contenidos de ficción a través de las ondas, en Internet, o en espacios híbridos donde las ondas, las TIC y el espacio público parecen inclinarse por el maridaje. ¿Cómo llamar a estos espacios de radio de modo que el propio nombre los defina? Godínez Galay (2015) teoriza sobre el concepto de radiodrama y los posibles subformatos en que se puede encuadrar la ficción radiofónica, enumerando hasta once subgéneros posibles: entre otros, el radioteatro, la radionovela, el monólogo, el radioarte, o el sociodrama. Curiosamente no alude entre ellos a la ficción sonora.

Sin embargo, parece que el término ficción sonora ha hecho fortuna. Es como si se pensase que ficción sonora suena, valga la redundancia, más moderno que radioteatro. Pero hay un inconveniente: ficción sonora no dice lo que es, no aporta información alguna sobre lo que ofrece. Ficción sonora no significa nada. Claro que la ficción podría producirse, se produce, sin sonido. Por momentos, o en toda su extensión, sobran ejemplos. Pero, con no menor frecuencia, son sonoras las ficciones del cine, del teatro. Todas son susceptibles de oírse. Se pronuncian palabras, hay efectos sonoros, música. Es preciso nombrar algo que difiere del cine, del teatro; no en la ficción, ni tampoco en el hecho de oírla, sino sólo en la ausencia de imagen más allá de la que el oyente crea en su cabeza, con su imaginación por medio del sonido: rostros, acciones, movimientos, escenarios, paisajes. Lo que no se oye, en el radioteatro (en la radio), en el audiodrama, en el universo audio, no existe. Eso es lo que distingue una cosa de otra. Importa, lo primero, el sujeto (radio, audio), sólo a continuación lo que allí pasa, la ficción (la novela, el teatro).

Mejor, pues, radioteatro o, si esto suena a pasado, audioteatro, audiodrama, más eufónico que audioficción, o radiodrama, radioficción, ficción radiofónica: ficción que se produce en la radio y en ningún otro sitio. Se emita o no se emita (hablar de radio carecería de sentido en tal contexto), otra manifestación del audiodrama tiene lugar ante el público, como originalmente se grababan ante el público los radioteatros. La gracia, aquí, reside en ver y comprobar que todo es falso: que los actores leen, que la voz de quien se supone una persona vieja la hace una persona joven, que al hombre seductor lo interpreta un gordito gracioso, que los efectos de sonido son un truco, $y$, de repente, encontrarse atrapado en el texto. Ese juego de niños en el que cada uno es lo que dice ser: creérselo, entrar en la propuesta, ser parte de ella. Pero lo que se cuenta es audio. Es, con efectos, con músicas, el poder evocador de la palabra. En la radio el sonido sustituye a la imagen. Cara al público, el sonido se impone a ella: lo que vemos es una cosa y lo que vivimos, a lo que de verdad asistimos, otra mucho más poderosa. El oído y la imaginación es lo que prevalece: «Un mundo mágico en el que lo que oyes no tiene nada que ver con lo que ves» (León, 2009). No hay otro movimiento que la construcción física de planos de presencia por parte de los actores, ni otro gesto que los correspondientes a la realización y a la mesa de sonido, sobre el escenario.

Cara al público se hacen, hoy, en Radio Nacional de España, Ficción sonora y los radioteatros de Gregorio Parra. Ya en 2006, en La Casa Encendida, se realizaron Radioteatro (de Mendés y Moreno) y Radioteatropiezas (de Volpini). A propósito de Ficción Sonora, el programa de la radio pública estatal que antes se mencionaba, Arquero apunta cómo este espacio radiofónico: 
y potenciado después por las tecnologías digitales, para representar frente al público una obra dramática. Los espectadores ven a los actores frente a un micrófono. El control de sonido se encuentra en el mismo espacio escénico y es visible. El público asistente percibe la ambientación sonora y los efectos de la banda de sonido con la que se recrean paisajes sonoros con texturas de sonido envolvente multicanal, en simultáneo. Los personajes entran y salen de escena, cambian de ubicación para situarse ante otro micrófono para construir un plano sonoro distinto. Todo ello forma parte de la puesta en escena y remite, curiosamente, a la frontalidad y al punto de vista recreado por los pioneros del cinematógrafo. En definitiva, Ficción Sonora fusiona los lenguajes del teatro, la radio y del cine (2015).

\section{Objeto de estudio: Cabeza de Vaca: Las vidas de Alvar Núñez, Herederos del Tiempo y El corazón de las tinieblas}

En la presente contribución se ofrecen tres aproximaciones distintas a la ficción dramatizada para radio a través de diferentes maneras de abordar la escritura y la acción, en las obras producidas por Radio Nacional de España: Cabeza de Vaca: Las vidas de Alvar Núñez, Herederos del tiempo y El corazón de las tinieblas. Tres intenciones, momentos y circunstancias muy diferentes entre sí que, para el guionista -Federico Volpini- y para la realización presentaron problemas concretos y necesitaron respuestas adecuadas sobre el lenguaje, el tiempo narrativo, el punto de vista y el particular juego de los planos sonoros.

La primera ficción dramatizada, Cabeza de Vaca: Las vidas de Alvar Núñez, realizada por el equipo técnico del Teatro 1, en diciembre de 1992, fue la última producción del cuadro de actores de Radio Nacional de España, disuelto poco tiempo después.

La segunda obra, Herederos del tiempo, Premio Italia 1998 a la mejor serie de ficción europea, era en su concepción un ejercicio creado para los alumnos del VIII Master de Radio Nacional de España y la Universidad Complutense de Madrid, quienes interpretaron esta pieza junto con algunos profesionales del extinto cuadro de actores.

La tercera, titulada en un inicio Un trabajo de Marlow sobre la novela de Joseph Conrad, grabada y emitida el año 2002 en castellano y en catalán por Radio 3 y Radio 4, fue una producción mixta que respondía a la propuesta de colaboración del Museo La Virreina de Barcelona para su exposición Joseph Conrad, El corazón de las tinieblas. En Barcelona, bajo la experta dirección de Armand Balsebre, se grabaron las voces. La obra se y se montó en Madrid, realizada con notable destreza por José María Silva, autor, como en Herederos del tiempo, de la música original. La producción dentro y fuera de Radio Nacional de España pudo ser pionera en este aspecto, como su emisión simultánea en dos idiomas del Estado.

\section{El trabajo en los tres audioteatros}

Es tarea del guionista anticipar realización, montaje, ambientación de músicas y efectos e interpretación: no se trata de imponer un criterio, sino de mostrar el camino y prever los accidentes. 
«El guión es la historia que se cuenta, los sitios visitados, lo que sucede en ellos y quiénes los visitan, pero también es el mapa, el manual de instrucciones» (Ortiz y Volpini, 2005). Debemos establecer cómo redactar esas instrucciones, dibujar ese mapa, a quién asignar la función de introducirnos en el territorio acotado y de qué manera va a narrarse lo que allí acontezca. A continuación, detallamos las decisiones tomadas en los tres radioteatros que referenciamos.

\subsection{El papel del narrador en una obra dramatizada}

En nuestra opinión, un dramático radiofónico, cualquier forma de audiodrama, debe, en la medida de lo posible, dar a la audiencia, al público, la sensación de que asiste a los hechos que se refieren. Se debería procurar, en consecuencia y en la medida de lo posible, prescindir del narrador. Quitar ese intermediario en un papel que sólo al receptor le corresponde: ver, percibir los paisajes y las formas, protagonizar la acción, estar allí. Sin embargo, hablaremos del narrador en los tres ejemplos elegidos.

\subsubsection{El narrador como valor añadido en la obra Cabeza de Vaca: Las vidas de Alvar Núñez}

Originariamente, se trataba de una serie en cuatro capítulos de una hora, para la televisión, sobre el libro Naufragios y comentarios de Alvar Núñez Cabeza de Vaca. El texto cambió de carácter al reescribirse para radio. Como sucede siempre, hubo que trasladar a sonido las imágenes; pero también se abrió la posibilidad de incorporar la reflexión, el comentario a los acontecimientos desde el punto de vista de un testigo improbable que se yergue entre los receptores y la historia. Ése es el papel tradicional de un narrador. El autor del guión no quiso, o no supo, resistirse a esta tentación.

¿Qué es la recreación de un hecho histórico, que además cuenta, en este caso, con el relato de su protagonista? Sin duda, respetar aquello que se sabe, si acaso discutirlo a partir de versiones diferentes o interpretaciones verosímiles de los hechos, e inventar - sin contradecir nunca a los hechos de manera arbitraria - en aquello que no se conoce. Los diálogos que nadie transcribió; los comparsas que tuvieron que estar y que en el libro no aparecen; los hechos anteriores, posteriores y paralelos que la Historia no recoge: allí se puede dar la creación. Para esta creación, un narrador ayuda.

En este radioteatro se suscitaron dos problemas principales: el lenguaje y la acción. ¿Tiene que ser simple el lenguaje y, la acción, lineal? En la radio, para un público mayoritario ¿hay que tender a la elementalidad? Al oyente, ¿debemos masticarle lo que pasa? Las palabras difíciles, las construcciones complicadas, ¿estorban la comprensión? Nuestra experiencia apunta a lo contrario: un texto bien leído, entonado, escrito con un ritmo que lo sostenga, se sigue perfectamente por muy enrevesado que parezca. ¿Que una palabra no se entiende?: la lectura le da sentido en el contexto y el oyente se deja, complacido, llevar. No se detiene. Acciones que se cruzan, saltos en el espacio y en el tiempo: no hay dificultad. En el guión está cuanto debe decirse; cuándo, cómo y dónde se produce la acción. El resultado está en los audios. 


\subsubsection{El narrador anfitrión en la obra Herederos del tiempo}

Herederos del tiempo es, de las tres obras seleccionadas, la que más se acerca a un supuesto ideal de reducir el papel del narrador al mínimo. Lo que implica, si esto se hace con rigor, no disimularlo bajo el disfraz de un personaje que cuenta lo que ha sucedido o va relatando lo que sucede según pasa. Es decir, un personaje que suplanta al narrador. En Herederos del tiempo el narrador introduce, presenta (otra de sus funciones canónicas); pero la escena tiene lugar sin él. Vayamos al ejemplo contrario.

\subsubsection{El narrador como centro de la historia en la ficción El corazón de las tinieblas}

Por encargo del museo barcelonés de La Virreina, corresponde a Jorge Luis Marzo y Marc Roig - los comisarios de la exposición Joseph Conrad, El corazón de las tinieblas - la propuesta de emitir un serial simultáneo con la exposición; propuesta que acompañaron con un nutrido cuerpo de notas que resultó de suma utilidad.

Forzado por la propia novela, en la obra El corazón de las tinieblas, Marlow el narrador, lo es todo. Él es la acción. Es quien cuenta lo que pasa. Y, a la vez, reflexiona sobre ello. Esa voz interior construye la obra entera. Cuanto sucede tiene que suceder acompañándolo.

\subsection{Una decisión sobre el lenguaje radiofónico en la obra Cabeza de Vaca: Las vidas de Alvar Núñez}

Es criterio de los autores de este artículo que, en el ámbito de la radio, un texto rico ayuda a la comprensión y no al contrario. En el siguiente fragmento de audio sobre la obra Cabeza de Vaca: Las vidas de Alvar Núnez, el protagonista acude junto al lecho en el que su madre agoniza. Aquí se muestra cómo, con un buen narrador, un texto complicado, que incluye algún término de uso poco corriente, fluye, sin que la voz decaiga ni la comprensión falle, de principio a final (Audio 1. Cabeza de Vaca: Las vidas de Alvar Núñez).

A continuación, en guión, el texto correspondiente a esa escena.

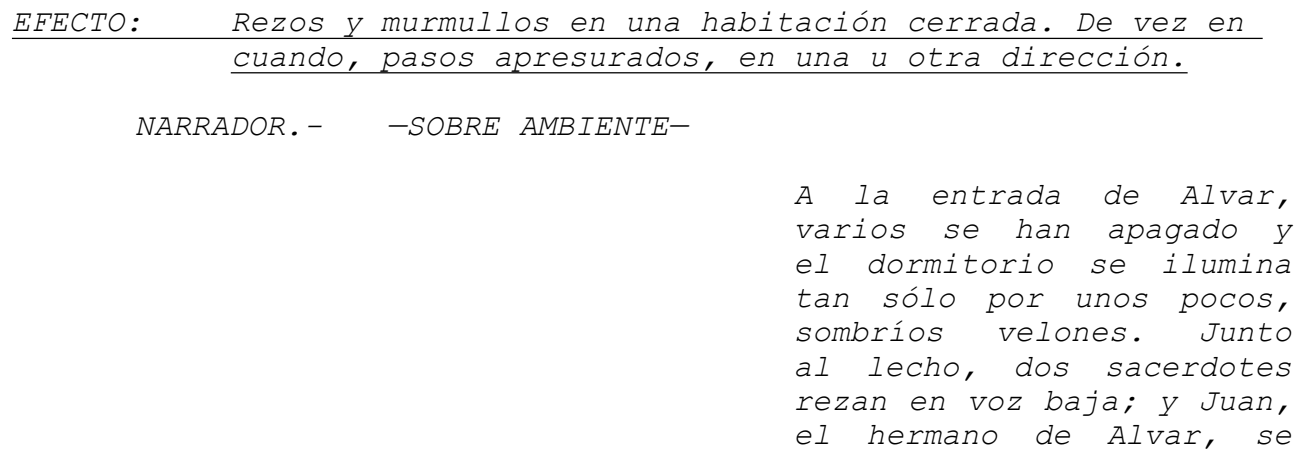


-Va entrando, en F.:

$\underline{M U ́ S I C A}$ diría que duerme. Al otro lado, derrumbada en un silión, el Ama llora. Una dama seca el sudor de la mujer agonizante. Los criados, entrando, $y$ saliendo, y moviéndose por la estancia, proyectan sombras fantásticas sobre suelos y paredes. Preside la habitación un inmenso retrato de don Pedro de Vera, en el que éste aparece tétrico, tenebroso, vestido de coraza y bien armado, pero con la cabeza descubierta. La barba blanca cae sobre su pecho. La

piel, cerúlea, amarillenta, como

muerta, se vuelve casi translúcida en el cráneo, totalmente desguarnecido. sólo los ojos, brillantes, terroríficos, como dos llamaradas verdiazules, están dotados de vida y hasta crean la ilusión del movimiento. En esos ojos fija Alvar la mirada, según se acerca al lecho, seguido, o, mejor, empujado por el mayordomo, que le obliga a arrodillarse al lado de su hermano. Arrodillado, Alvar sigue notando en su nuca las terribles pupilas del retrato. Alvar se agita, nervioso. Arriesga una ojeada $y$ de hecho le parece que el retrato le mira. Una sombra que pasa frente al cuadro distrae por un momento la atención del muchacho: es una de las mujeres, que lleva un cuenco de cerámica, lleno de agua enrojecida. Sobrecogido, el niño ahora no puede apartar los ojos de ese cuenco, hasta que desaparece por la puerta. 
-fuera MÚSICA. TERESA. - T TUY DÉBIL¡Alvar...!

-vuelve EFECTO rezos, murmullos, etc. (AMBIENTE ANTERIOR)

NARRADOR.- $\quad$-SOBRE AMBIENTE-

-alejamos AMBIENTE

_EFECTO: puerta

cerrándose con suavidad.

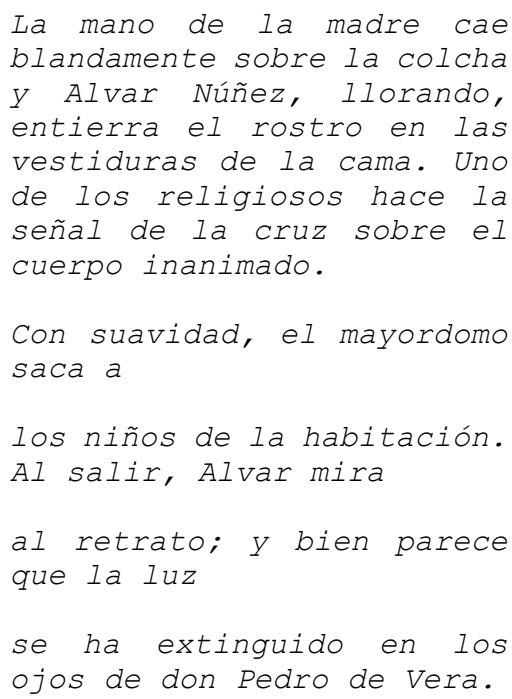

Apuntemos en esta escena el contraste visual de las imágenes. La mujer agonizante, las personas que rezan, el retrato de don Pedro de Vera, estático y, en movimiento, los criados, la sombra que cruza con el cuenco de agua ensangrentada.

\subsection{La interpretación de los actores}

El radioteatro pide voces trabajadas de forma que los actores expresen sentimientos sin necesidad de verbalizarlos. El segundo audio de Cabeza de Vaca: Las vidas de Alvar Núnez tiene que ver, también, con la interpretación. Desde su cuarto, Alvar escucha una conversación entre la tía, a cuyo cuidado han puesto a los hermanos, y el mayordomo de la casa, don Martín (Audio 2. Cabeza de Vaca: Las vidas de Alvar Núñez).

A continuación, en guión, el texto correspondiente a esa escena. 
JUANA. -

MARTÍN.-

JUANA. -

MARTÍN. -

JUANA. -
iEste no es sitio para educar a un niño! ¿Qué vamos a hacer tú, un viejo revenido, y yo, una solterona, en esta casa, con dos chiquillos que pronto empezarán a hacernos preguntas, a crecer; que se volverán hombres sin que nos demos cuenta? (APENADA) No, Martín: tenemos que atender a que se eduquen, $y$ sea como exigen su sangre $y$ su linaje.

\section{(INTENTA PROTESTAR)}

¡Pero doña Juana, yo, Yo le juré a su madre que la cuidaría!

(LE INTERRUMPE)

¡Y así será, Martín! Tú marcharás con ellos.

(DEPRISA; COMO QUIEN QUIERE ZANJAR UNA CONVERSACIÓN QUE LE ES DOLOROSA)

Ya he enviado recado a los duques de Medina Sidonia. Hace tiempo que estaba concertado.

(SE LE ESCAPA UN SOLLOZO)

iEsta desgracia sólo acelera las cosas!

iPero tan de repente!; itan deprisa! ¿No sería mejor...?

(LE CORTA NUEVAMENTE, ENÉRGICA)

¡Lo que ha de hacerse, que se haga cuanto antes! Partiréis esta noche. He dado orden de prepararlo todo. 


$\begin{array}{ll}\text { MARTIN. - } & \text { (COMO SIN FUERZAS) } \\ & \text { iEsta noche! } \\ \text { JUANA. - } & \text { iEsta noche, Martín!... Ve a } \\ & \text { recoger tus cosas. } \\ & \text { (HACE UNA LARGA PAUSA. } \\ & \text { EMOCIONADA) } \\ & \text { VOY a echarte de menos. } \\ & \text { (CON UN NUDO EN LA GARGANTA) } \\ & \text { iDoña Juana...! } \\ \text { MARTÍN. - } & \text { (EXPEDITIVA) } \\ & \text { iVé! iVé! iMárchate ya, } \\ & \text { Martín! iNo digas nada! }\end{array}$

No lo dicen, pero ¿no es evidente que Martín y doña Juana son amantes? ¿Y no sufrimos con ellos y por ellos? Ésa es la cualidad que se le exige a una actriz o un actor en la radio: dar, sólo con la voz, cada intención; mostrarnos su carácter, hasta su complexión, sus rasgos, como el ciego que sigue las líneas de la cara con los dedos; decirnos, sin decirlo, lo que sienten; por qué; cuándo engañan o no; dónde y cómo se mueven... Una vez más, es magia. Y la magia pide que haya magos. Las voces y los técnicos, atentos a la realización: los operadores de toma de sonido, los montadores musicales, los especialistas en efectos.

\subsection{Profundidad y planos sonoros}

Una buena realización atiende a la profundidad y al juego simultáneo de los planos sonoros. El tercer audio de Cabeza de Vaca: Las vidas de Alvar Núñez tiene que ver con esta condición que parece evidente: no hay paisaje, no hay espacio, no hay verdad, si la plasmación sonora de los distintos planos y la relación dinámica entre ellos se descuida.

Acompañados por el mayordomo, Alvar y su hermano viajan hacia Medina Sidonia. Un encuentro se produce en mitad de la noche (Audio 3. Cabeza de Vaca: Las vidas de Alvar Núñez).

A continuación, en guión, el texto correspondiente a esa escena. 
EFECTO: grillos. Caballos resoplando.

-sobre EFECTO:

EFECTO: carruaje en marcha

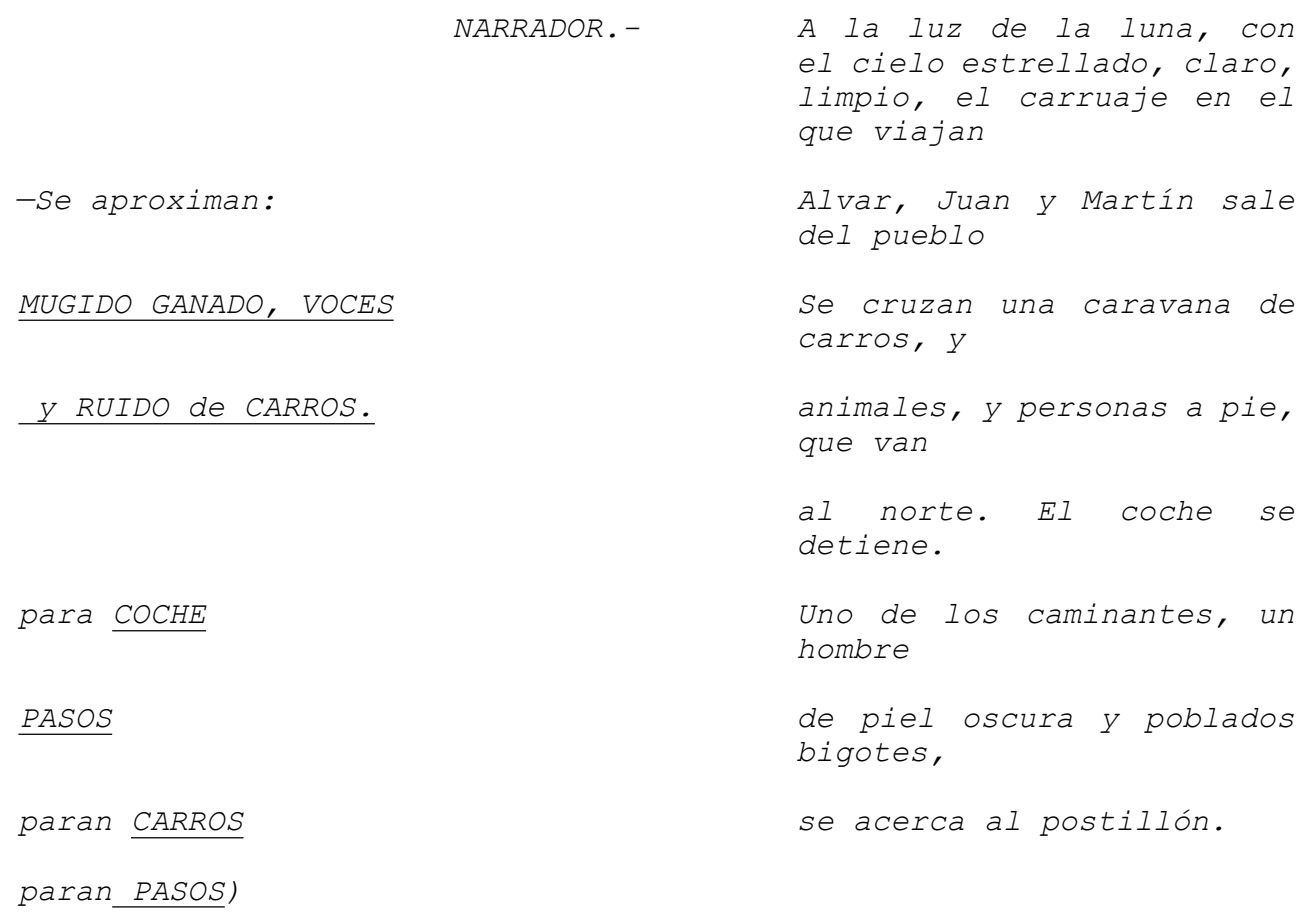

EFECTO: cascos caballo; nervioso.

-siguen GRILLOS; MUGIDOS, etc.

HOMBRE.-

¡Buen hombre! ¿No tendrías una hogaza de pan y algo de queso? iLlevamos una mujer enferma, $y$ hoy no se va a comer en todo el día! 


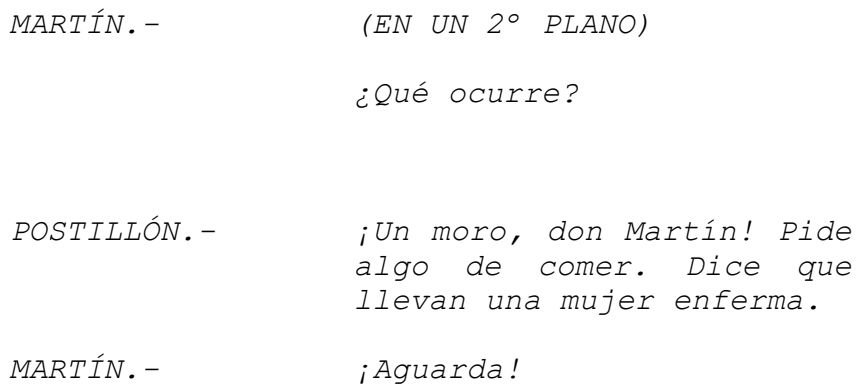




$\begin{array}{ll}\text { POSTILLÓN. - } & \text { ¿Vais lejos? } \\ \text { HOMBRE. - } & \text { (GRITA, ALEJÁNDOSE YA) } \\ & \text { iA Hornachos! } \\ \text { POSTILLÓN. - } & \text { iPues que la Providencia } \\ & \text { OS acompañe! iArre, mula! } \\ & \text { iCaballo! }\end{array}$

POSTILLÓN.¡Caballo!

RESTALLAR látigo

EFECTO: arrancar carruaje. Mientras se aleja, siguen, EN SU PLANO, ganado y grillos.

El audio nos presenta el camino y el interior del carruaje. Fuera, los caballos, el postillón y los moros definiendo dos planos diferentes en los que se produce la conversación. Dentro, otro ámbito, otro plano, los pasajeros, que despiertan.

La escena discurre sin que los sonidos, los espacios, se impongan. Cada voz, cada ruido, en su plano, cumple con su función; alcanza el protagonismo que le corresponde en un conjunto armónico.

Los realizadores inexpertos tienden a saturar de sonido cada escena; a apabullar al receptor con una tormenta de músicas y efectos que no le dan respiro: es el recurso, consciente o inconsciente del ruido. Esto, que los actuales medios técnicos propician, sustituye la acción por el barullo y el hechizo - la interpelación a la sensibilidad y a la inteligencia-, por el aplastamiento.

\subsection{El tratamiento del tiempo narrativo en Herederos del tiempo}

En Herederos del Tiempo el problema fue, justamente, el tiempo: la acción se produce, capítulo a capítulo, en dos tiempos diferentes que se cruzan. Los tres protagonistas principales: el mago Prusias, Sofía y Nico, vienen del futuro. Cada mañana se despiertan en el día anterior, mientras que los demás personajes van, como hacemos todos en la vida real, hacia ese futuro que tenemos delante.

Comienza la historia en un presente desde el que los protagonistas serán arrebatados hacia un remoto pasado. Es importante que el oyente, sólo por el sonido, aprecie la diferencia entre uno y otro incluso antes de que los personajes hablen (de hecho, estos no se referirán a ello). ¿Cómo generar un sonido claramente distinto que los identifique? 
La solución - aprovechar la calidad del sonido como recurso para marcar dos tiempos diferentes, presente y pasado, que se combinan dentro de una misma escena - fue asignar al tiempo actual (presente) un tratamiento monoaural, frío, distanciado y plano, mientras que el tiempo en el que de verdad sucede todo tiene un sonido estéreo rico, brillante, envolvente.

En el siguiente audio la acción se sitúa en 1997. Dos jóvenes, Sofía y Nicomedes, visitan la finca en la que transcurrió su infancia. De una higuera pende un harapo mugriento, gastado por el sol y por la lluvia. Por broma, Nicomedes corta la cuerda. Y el atado se volatiliza, como si se hubiese convertido en polvo (Audio 4. Herederos del tiempo).

A continuación, en guión, el texto correspondiente a esa escena.

SOFÍA:

NICO:

SOFÍA:

NICO :

SOFÍA:

NICO :
(ACERCÁNDOSE A LA CARRERA. SIN ALIENTO)

¿Eres bobo, o qué pasa?

(EN UN SUSURRO)

¡Jodé, cómo está esto!

(BAJANDO LA VOZ TAMBIÉN)

¡Está hecha una ruina!

iMira, ése es el bulto! iAhí, colgado de la higuera! iTe apuesto a que ése es el ahorcado del campo de Melina! iEl que le cuidaba los sembrados!

( INCÓMODA)

¡Nico! iQuieres estarte quieto!

(EN UN PLANO MÁS LEJANO)

¡Qué guarro! iEstá como encerado!

(HACE ASPAVIENTOS)

¡Uff! iQué cantidad de mierda! ¿Y la cuerda? ¡Agggg! Da asco tocarla. 


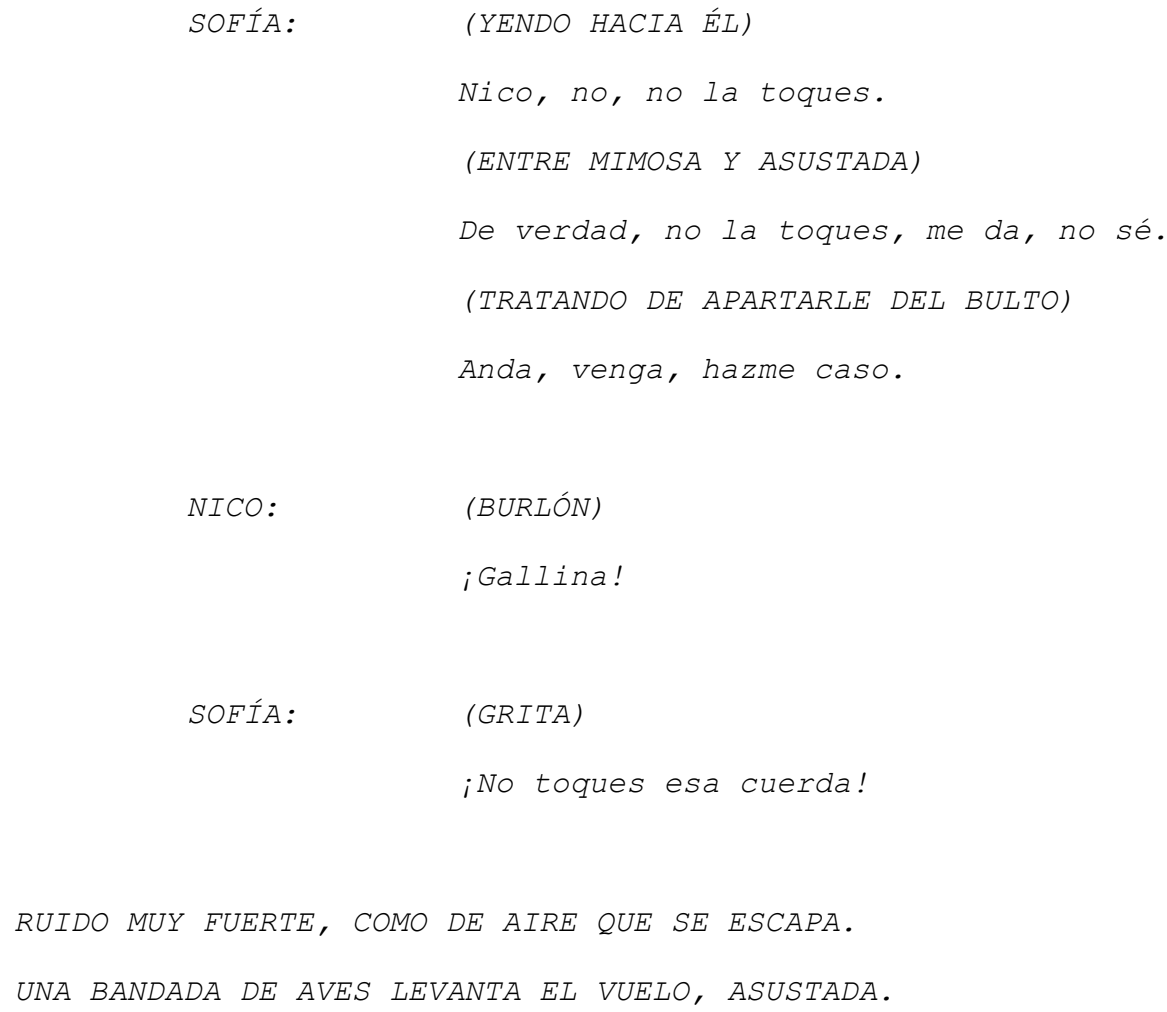

Como hemos oído, en el tiempo actual (presente), el sonido es pobre: hasta los golpes musicales, donde los hay en el capítulo, resultaban estridentes, desabridos. Sólo los sonidos relacionados con el pasado: el moscardón que ronda el bulto del ahorcado y la desaparición de éste, tienen volumen, brillo.

Pero el verdadero problema en Herederos del tiempo fue de guión. Cómo conciliar las dos direcciones en las que se desarrolla la historia: tres personajes retrocediendo en el tiempo día a día y relacionándose, sin cometer errores, con el resto de la acción, que avanza normalmente, del pasado al futuro. La solución fue, claro, escribir dos estructuras completas, confrontándolas luego capítulo a capítulo. En esto y en su planteamiento como gran producción, con veinte guionistas (alumnos del Master) coordinados sobre esa pauta —un proyecto que jamás llegó a realizarse—, reside el posible interés de la obra.

\subsection{Imponer una apariencia al personaje y contar una historia a la que no asiste el oyente}

¿Es conveniente, en los radioteatros, utilizar actrices y actores famosos del cine, de la televisión o del teatro? Cierto, atraen a la audiencia y eso beneficia al género, pero es verdad también que entre las bazas de la radio está la de no ver quien te habla. Como en el libro (cuánta decepción cuando vemos en la pantalla aquella novela que 
amamos), en un radioteatro el personaje es el que nosotros le ponemos; con su rostro, su cuerpo. No los de la actriz o el actor que lo interpretan. Un rostro conocido y ya no hay magia. ¿Compensa? Salvo, tal vez, un cameo, para un personaje concreto, apostaríamos por que no, pero aun así es una decisión ardua y un problema que debe resolverse.

La participación en El corazón de las tinieblas de Constantino Romero, rostro popular como presentador de espacios televisivos y una voz reiterada en el cine, que el doblaje prestaba a los personajes duros, suponía, asimismo, un aliciente y un escollo. Su presencia garantizaba el interés del público: aportaba la fama a la interpretación. Por otro lado, Marlow, con Constantino, no podía ser Marlow; era Constantino o, peor, el circunspecto, el contenido Marlow, podía transformarse en Harry el Sucio (Constantino Romero era el doblador de Clint Eastwood). Y no habría manera de borrar esa imagen en la cabeza del oyente. La generosidad de Constantino Romero, prestándose a interpretar a Marlow en las particulares condiciones que una emisora pública podía proponerle era, también, un regalo envenenado. Que aceptamos.

El problema principal en El corazón de las tinieblas fue la decisión sobre el punto de vista y el juego de los planos sonoros. Lo primero no admitía opción: a Marlow, el narrador, es imposible obviarlo. Dialogar El corazón de las tinieblas supone (Apocalypse Now, F. Coppola, 1979) construir una cosa distinta. Pero una narración en primera persona a lo largo de doce capítulos, por mucho que se acompañe con músicas y efectos, y haya digresiones en escenas aisladas, no es un radioteatro; al oyente se le refieren los hechos, no está allí. Hay que acudir a otro recurso. Hacer que, con el apoyo ocasional de esos apuntes dramatizados, sean los efectos los que busquen situarnos en el lugar en el que se desarrolla la obra.

\subsection{Una narración paralela resuelta con efectos}

No es, hoy, recurso excesivamente original, pero sí muy eficaz situar al oyente allí donde suceden las cosas acudiendo sólo a los efectos de sonido, por medio de una segunda línea de narración que se resuelve en un plano distinto del principal. Un ejemplo de El corazón de las tinieblas: Marlow, en la desembocadura del Támesis, esperando a que suba la marea, refiere a sus compañeros el viaje que hizo Río Congo arriba. El sonido, por debajo de Marlow, nos sustrae del tiempo (finales del siglo XIX, principios del siglo XX) y el lugar (el Congo africano bajo la dominación belga) en el que se produce la acción que se va a referir; y nos deja, con su oficial, en la cubierta de una nave romana (Audio 5. El corazón de las tinieblas).

A continuación, en guión, el texto correspondiente a esa escena.

-Por debajo de Marlow:

MARLOW. -

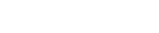

Imagínense

Ios sentimientos del capitán de 
GOLPES CÓMITRE Y

BATIR DE LOS REMOS

DE UNA GALERA

UNA BANDADA DE AVES

LEVANTA EL VUELO

EN LA ESPESURA

GALOPE DE UN CABALLO

RISAS. VOCES, RUIDO ARMAS

-Vuelve:

SUAVE GOLPEAR OLAS CONTRA

EL CASCO DEL BARCO uno de esos navíos romanos

$d e s t$ i $n$ a d o inesperadamente a

viajar al Norte.

Una

trirreme deI

Mediterráneo.

Imagínenlo aquí.

Un muy civilizado romano. Tras

cruzar las Galias, llegando en

barco, remontando este río con

aprovisionamientos, u órdenes,

- Io que sea, para algún puesto interior, en medio de tribus rebeldes $y$ ritos tenebrosos. Pantanos, bosques, un cielo color de plomo, frío, niebla, bruma, toses, enfermedades. Hombres salvajes siempre al

acecho.

De vez en cuando, el barco llega

a un campamento militar perdido en cualquier parte, como una aguja en medio de un pajar. Nuestro romano no tiene ni su vino de Falerno, ni sus buenos platos de cordero, ni a su familia cerca. Todo es oscuro y hostil. 
La selva (inglesa en este caso), los salvajes britanos, el barco de una potencia invasora... Si al menos parte de esto hubiera podido hacerse en estudio, al tiempo que se grababa la palabra. El chapuzón que se produce según salta el personaje; ese disparo que los actores oyen y ante el que pueden reaccionar de un modo más verosímil. Con frecuencia los efectos se incorporan a los espacios dramáticos sin que lleguen a escucharlos los intérpretes. Es más, cuando actrices y actores llevan auriculares y los oyen, la gestualidad, imprescindible para la interpretación, se resiente. La voz registra no sólo el rostro crispado, la sonrisa, sino también el gesto, el movimiento; y ese movimiento aporta verosimilitud.

Por múltiples motivos (¡cómo se nota cuando el intérprete se está escuchando!), el radioteatro, salvo en el caso del narrador, invitado a transitar sobre la música, debiera hacerse sin auriculares. Y ayudarse con efectos in situ. Lo habitual es justo lo contrario: los efectos, muchas veces, se incorporan en la postproducción. En El corazón de las tinieblas, grabadas las voces en Barcelona y hecha la producción, añadidos los efectos en Madrid, se juega sobre un ciclorama neutro: pantalla monocroma que después será selva. Excelentes actores consiguen situarse así en la acción. Acción que, en el caso de El corazón de las tinieblas, sucede en un segundo plano, acompañando a la voz. En ocasiones es a ese segundo plano, no a la voz, hacia donde hay que dirigir la atención del oyente.

\subsection{Traslación de la atención a un plano distinto del principal}

Otro escollo que surgió y al que llevábamos enfrentándonos tiempo fue el de la transferencia de la atención a planos diferentes del principal, extremo que en $E l$ corazón de las tinieblas era de decisiva importancia. Y algo que sucede detrás, a igualdad de fuente de sonido (por ejemplo, la voz), en audio sonará siempre más bajo. Por fortuna el oído es selectivo. Basta con que, aprovechando una mínima pausa, en otro plano se produzca una acción, o un diálogo, con carácter suficiente - cualquier episodio violento - , para que la atención se centre en ese plano de inmediato (Audio 6. El corazón de las tinieblas).

A continuación, en guión, el texto correspondiente.

SILBIDO LANZAZO Y GOLPE SECO

MARLOW. -

NEGROS . -

(MURMULLO ASUSTADO)
JOVEN NEGRO.- iNo pega! iNo pega! (SIGUE GRITANDO) 
Si esa acción se prolongase, independientemente de lo que dijera el narrador (o cualquier otra acción en primer plano), el oyente querría escuchar qué está pasando.

\section{Conclusiones}

A partir de nuestra aproximación a la ficción dramatizada para la radio, por medio de las obras Cabeza de Vaca: Las vidas de Alvar Núnez, Herederos del tiempo y El corazón de las tinieblas, desglosamos las siguientes aportaciones sobre la naturaleza del radioteatro.

Crear, en el transcurso del tiempo que una obra dramática dura, un espacio. Darle a ese espacio, solamente por medio del sonido, unas dimensiones, una profundidad y una apariencia física. Habitarlo y generar acciones y diálogo. Es, en efecto, eso lo que hace el radioteatro, el audiodrama.

Voces experimentadas en un medio que no es el cine, ni el teatro, ni la televisión, ni tampoco el doblaje, donde se apoya el actor sobre el gesto visible, la expresión, sobre la imagen. Dar vida a acciones, sentimientos, ocupar un espacio sólo con la voz. Con realizadores, montadores, técnicos, profesionales. Se echa de menos aquel maravilloso Teatro Uno de Radio Nacional de España: un espacio de grandes dimensiones en el que los actores evolucionaban construyendo, como se debe, físicamente los planos de presencia a partir de un primer plano que se materializa en un único micrófono, pendiente de una pértiga con un reservado independiente para la narración. Igualmente, el teatro contaba con la cabina de control en alto, como ventana desde la que se abarcaba cuanto ocurría; los dispositivos para efectos: escaleras de piedra y de madera, puertas, timbres; $\mathrm{y}$, al fondo, la cámara ecoica y una cámara anecoica que no solo absorbe las reflexiones del sonido sino que apaga sus armónicos: «mata»el sonido.

El radioteatro es magia. Cada vez son más las universidades, los colegios, que lo incluyen como materia en sus currículos. No hay, en la radio, género más rico, más lleno de posibilidades, más sugerente y, salvo el libro, no hay ámbito más adecuado que la radio para que en él viva la ficción. No hay propuesta que pueda comparársele, en donde la narración se disfrute desde dentro, en primera persona, se haga de quien la escucha. Más visual que la imagen. Y, al contrario que el libro, que permite pararse, releer, volver atrás; urgente como la vida misma. Pasa según se oye. Es la emoción servida en el momento.

Una imagen vale más que mil palabras. Una palabra genera mil imágenes. La propia Academia de las Artes y las Ciencias Cinematográficas de España, la Academia del Cine, le ha manifestado al radioteatro su interés y su apoyo (CINE\&TELE, 2015).

Oferta diferenciada, única, muy competitiva, la calidad de su factura explica su pervivencia y el interés que, hoy, vuelve a despertar. Muy poco a poco, en lo que a las grandes cadenas se refiere. Y en el camino se va perdiendo conocimiento, oficio: el tejido que le da consistencia y que hace de él un arte. Todo hoy puede hacerse. Pero con mucha mayor dificultad y, muchas veces, con peor resultado. Reaccionar ante esta situación es necesario, apremia.

Tendrá, sí, que adaptarse a las nuevas audiencias. Un sonido envolvente, brillante, agilidad, combinación de ritmos, contenidos más breves. Pero el hechizo está ahí. Y surte efecto. El mismo para todos y diferente para cada persona; un mundo, una burbuja, es la ficción dramatizada en audio. 


\section{Bibliografía}

Arias García, E. (2008) . «El serial radiofónico como producto de creación: análisis de la estructura del primer capítulo de 'Ama Rosa'», en $I+C$ Investigar a comunicación: Investigar la comunicación. [Actas Congreso Internacional Fundacional AE-IC]. Santiago de Compostela.

Arquero Blanco, I. (2015). «De vuelta a la ficción sonora». Espéculo. Revista de estudios literarios, 54, pp. 155-168.

Ayuso, E. (2013). «La recepción de la radio dramática en España (desde la postguerra a 1971)». Index.comunicación. Revista científica en el ámbito de la comunicación aplicada, 3, 1, pp. 167-185.

Barea, P. (1994). La estirpe de Sautier. Madrid: El País.

- (2002). «70 años de 'Todos los ruidos de aquel día'. Zer. Revista de estudios de comunicación, 12.

- (2003). «Radioteatro de humor 1950-1974». En A. Romero Ferrer y M. Cantos Casenave (Ed.) La comedia española, entre el realismo, la provocación y las nuevas formas (1950-2000) [Actas IV y V Congreso Internacional de Historia y Crítica del Teatro de Comedias]. Cádiz.

- (2004). «Dramaturgos en el aire». ADE teatro. Revista de la asociación de Directores de escena de España, 99.

Balsebre, A. (2001). Historia de la Radio en España. Volumen I (1874-1939). Madrid: Cátedra.

- (2002). Historia de la Radio en España. Volumen II (1939-1985). Madrid: Cátedra.

CINE\&TELE (2015). «El audiodrama entra en la academia». Recuperado de http://www. cineytele.com/2015/04/08/el-audiodrama-entra-en-la-academia/ (Fecha de acceso: 12/12/2016).

Díaz, L. (1993). La radio en España. 1923-1993. Madrid: Alianza Editorial.

Franquet, R. (1999). Història de la radiodifusió a Catalunya. Barcelona: Generalitat de Catalunya.

Godínez Galay, F. (2015). «Revisando el radiodrama en la actualidad». Revista Comunicación y Medios, 31, pp. 85-101.

González Alfonsea, M. (2016). «De los dorados 50 y 60 al declive de la radionovela en la radio en España». [TFG. Universidad Rey Juan Carlos]. Madrid.

Gordillo Álvarez, I., Guarinos, V. y Ramírez Alvarado, M. (2011). «El relato audiovisual transmediático. Esquivando los media tradicionales. Estudios de caso y propuestas creativas». Trípodos, pp. 577-586.

Guarinos, V. (1999). Géneros ficcionales radiofónicos. Sevilla: MAD.

León, P. (2009). «Cuando suena como la jungla». Madrid: El País.

López Merayo, A. (2012). «El género negro y policíaco en los seriales radiofónicos». En J. Sánchez Zapatero y A. Martín Escribá (Ed.). El género negro: el fin de la frontera. Santiago de Compostela: Andavira.

Marta Lazo, C. y Ortiz Sobrino, M. A. (2013). «Gestión de los fondos documentales en Radio Nacional de España». El profesional de la Información, 22, 5. DOI: 10.3145/epi.2013. sep.04.

Ortiz Sobrino, M. A. (2012). «Radio y post-radio en España: una cohabitación necesaria y posible». Revista Área Abierta, 12, 2, pp. 1-16. 
— y Marta Lazo, C. y Martín Pena, D. (2016). «La formación de competencias profesionales en los estudiantes de Comunicación Social de las emisoras universitarias en España y Portugal: situación y resultados asimétricos». Revista Signo y Pensamiento, 68, 35. DOI: 10.11144/Javeriana.syp35-68.fcpe.

Ortiz Sobrino, M.A. y Volpini Sisó, F. (2005). Diseño de programas en radio. Guiones, géneros y fórmulas. Barcelona: Paidós.

Rodero, E. y Soengas, X. (2010). Ficción radiofónica. Madrid: Instituto RTVE.

SGAE (2011) «Teatro contemporáneo español en la radio». Recuperado de http://docplayer. es/8995177-Teatro-contemporaneo-espanol-en-la-radio.html (Fecha de acceso: 01/07/2016).

Zumeta, G. (2015) «La SER recupera el radioteatro por Navidad». Recuperado de http:// www.gorkazumeta.com/2015/12/la-ser-recupera-el-radioteatro-por.html (Fecha de acceso: 01/08/2016).

\section{Archivos sonoros}

Todos los archivos sonoros son de RTVE y se encuentran disponibles en https:// revistas.ucm.es/index.php/ARAB

Cabeza de vaca: las vidas de Alvar Núñez (Audio 1, 2 y 3).

Narrador: José María del Río

Juana: Aurora Vicente

Martín: Pablo Jiménez

Hombre: Luis Alonso Carrasco

Postillón: Inocencio Martín

Alvar: Lourdes Guerras

Reparto: Bernardo Mingo, Federico Volpini, José Antonio Genís, J. José Rubio, Pilar Quintana, Isabel Ruiz Lara, $\mathrm{M}^{\mathrm{a}}$ del Carmen Mora, $\mathrm{M}^{\mathrm{a}}$ Isabel Aguilera, Eloísa Mateos, Javier Bellido, José Antonio Ramírez

Realización: Equipo Técnico del Teatro 1

Guión original: Federico Volpini

Montaje musical: Manuel Ramos

Efectos Especiales: Bernardo Mingo y Joaquín Úbeda.

Herederos del tiempo (Audio 4).

Sofía: Lourdes Guerras

Nico: Ángel Marco

Reparto: Luis Alonso Carrasco, Roberto Cruz, Rodolfo Santarfieri, Pepa Terrón, José Antonio Ramírez

Dirección y guión original: Federico Volpini

Música original: José María Silva

Realización: Roberto Cruz

Edición digital: Benigno Moreno y Miguel Ángel Coleto.

El corazón de las tinieblas. (Audio 5 y 6)

Marlow: Constantino Romero

Reparto: Arsenio Cursellas, Carmen Alarcón, Félix Benito, Juan Antonio Bernal, Jaume 
Comas, Joan Cornellas, Vicente Gil, Ramón Hernández, Marta Martorell, Josep Ma Ullot, Lluis Marco, Alberto Mieza, Josep Planas, Rafael Turia Adaptación para radio: Federico Volpini

Traducción al catalán: Armand Balsebre

Notas al texto y versión sala: Jorge Luis Marzo y Marc Roig

Música original: José María Silva

Dirección en Barcelona: Armand Balsebre

Realización en Madrid: José María Silva y Manuel Álvarez

Toma de Sonido: Antonio Flores y Plácido Navarro. 